\title{
Wave Energy Plants for the Black Sea - Possible Energy Converter Structures
}

\author{
Loránd SZABÓ, Claudiu OPREA \\ Department of Electrical Machines, Technical University of Cluj \\ P.O. Box 358, 400750 Cluj, Romania \\ E-mail: Lorand.Szabo@mae.utcluj.ro
}

\begin{abstract}
It is crucial for the mankind to develop clean renewable energy sources. Ocean energy is one of the candidates being a huge, yet unexploited renewable energy source on the Earth. Preliminary surveys show that marine power has a potential to supply a significant part of the future energy needs. Hence all the researches done in the field of the wave energy conversion should be of real interest. In this paper the wave energy potential of the Black Sea near the Romanian coasts, a possible power take off system to be set up here, respectively a comparative study on two possible linear generators to be used in such wave energy power converters will be presented.
\end{abstract}

Index Terms-Linear generators, marine energy converters, renewable energy resources, wave energy.

\section{INTRODUCTION}

Renewable energy sources, for the most part originating from the Sun's radiant energy, are ever-present, long-lived, and essentially free of carbon emissions. They have the potential to respond to global sustainability and environmental, safety, social, and economic goals [1]. Benefits of renewable energy systems are stated in a political declaration agreed to by 154 nations at the 2004 International Conference for Renewable Energies, held in Bonn as a follow-up to the 2002 World Summit on Sustainable Development, held in Johannesburg.

The benefits of renewable energy resources assure energy-supply security, equity and development, improved health, overcoming peak oil-price fluctuations, the provision of clean water, neatly fitting with energy efficiency measures, and climate change mitigation.

Renewable energy sources include hydropower, modern biomass, solar, wind, geothermal, and ocean energy. Together they currently contribute the equivalent of $7 \%$ of the World's primary energy use.

Day by day the share of renewable energy in electricity consumption is increased. For this the EU has set a target of $12 \%$ by 2010 . As a result of the political commitments the renewable energy industry is developing around the world being one of the highest priorities of mankind.

To these trends Romania also had been aligned in 2002 according to the medium-term National Strategy for the power sector. In this is pointed out as the main future objectives are to develop efficient energy markets, to ensure higher quality and security of supply and to comply with EU standards regarding the rational use of energy and environment protection.

Worldwide wind power is clearly at the forefront of the renewable energy sources. The total installed wind power capacity round the world by now stands over $60 \mathrm{GW}$. In 2006 only in the EU near $7.6 \mathrm{GW}$ of wind power capacity was installed, worth over 9 billion $€$. This means an increase of $23 \%$ compared to 2005 [2].

Ocean energy is a yet unexploited renewable energy source on our planet. Preliminary surveys show that marine power has a potential to supply a significant part of the future European energy needs [3].

The three most well developed technologies for deriving electrical power from the ocean include tidal power, wave power and ocean thermal energy conversion. From these possibilities the wave energy conversation seems to have the greatest general application.

The World Energy Council has estimated the global ocean wave energy over $2 \mathrm{TW}$ (which means $17,500 \mathrm{TWh} /$ year). From this it has been estimated that the practical economic contribution of the wave energy converters could be 2,000 TWh/year, similar to current installed nuclear or hydroelectric generation capacity.

Such generating capacity could result in up to 2 billion tones of $\mathrm{CO}_{2}$ emissions being displaced from fossil fuel generation per year, similar to current emissions from electricity generation in the US [4].

There are several compelling arguments for using the wave energy technology [5]:

i.) By its high power density it is one of the lowest cost renewable energy sources.

ii.) The wave energy is more predictable than solar and wind energy, offering a better possibility of being dispatched to an electrical grid system.

iii.) The conversion of ocean wave energy to electricity is believed to be one of the most environmentally benign ways to generate electricity, hence it does not render any waste that has to be stored or destroys the environment.

iv.) The wave energy conversion devices can be located far enough away from the shore (offshore) that they are generally not visible.

As it was stated out in numerous research reports although waves represent a free and clean source of energy, capturing this energy inevitably needs large capital investments and can have some impacts on the environment, which must be taken also into account [6]. 


\section{The Wave Power In The Black SeA}

The power potential for waves can be described as units of power per meter of wave crest length. The greatest power in the wave fronts is about $100 \mathrm{~kW} / \mathrm{m}$ in the Atlantic Ocean SW of Ireland, in the Southern Ocean and off Cape Horn [7].

Large portions of the world's potential wave energy resources are also found in sheltered waters and calmer seas, which often exhibit a milder, but still steady wave climate. Examples are the Baltic, the Mediterranean and the Black Sea [8].

Unfortunately the wave power in the Black Sea is moderate. Precise data regarding the wave energy potential in the Black Sea near the Romanian coasts could not be found in any available bibliographical resources.

Hence we were constrained to look for indirect information on the wave energy potential from other similar sheltered seas and on other available parameters of the waves in the Black Sea [9], [10].

Relations between the mean wave height $\left(h_{w}\right)$ and mean energy density, respectively mean power could be established for sea depths of $5 \div 10 \mathrm{~m}$ (Fig. 1).

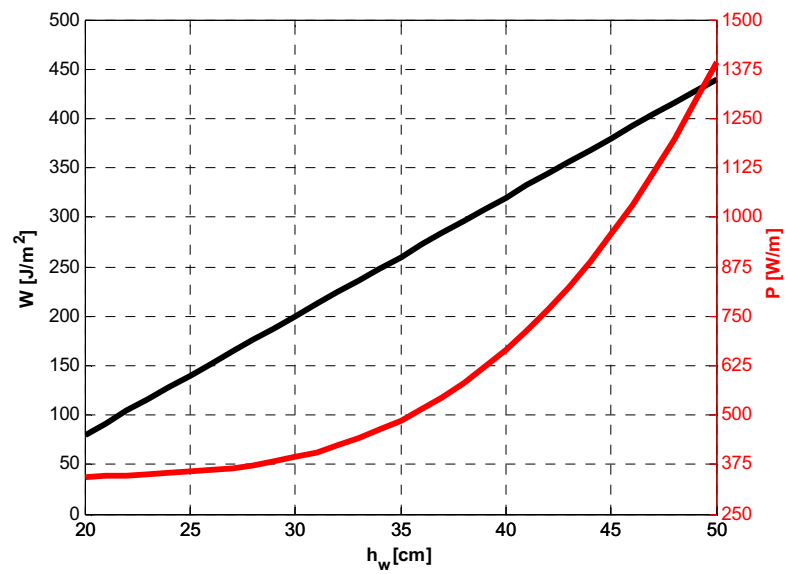

Fig. 1. The mean energy and power densities vs. the mean wave height

In [11] the monthly mean wave heights in the Black Sea obtained upon 35 years long measurements are given (see Fig. 2).

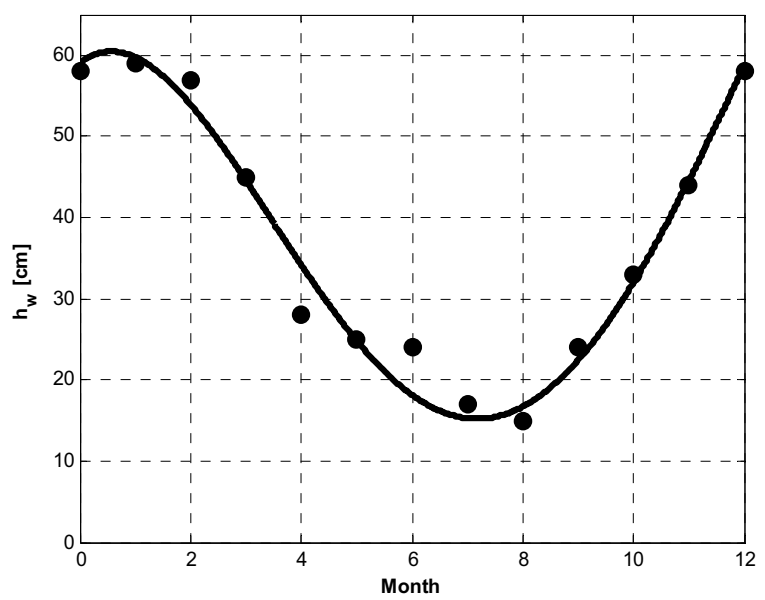

Fig. 2. The monthly mean wave heights
Combining the data presented in Figs. 1 and 2 the monthly mean power density of the wave energy in the Black Sea was computed (see Fig. 1c).

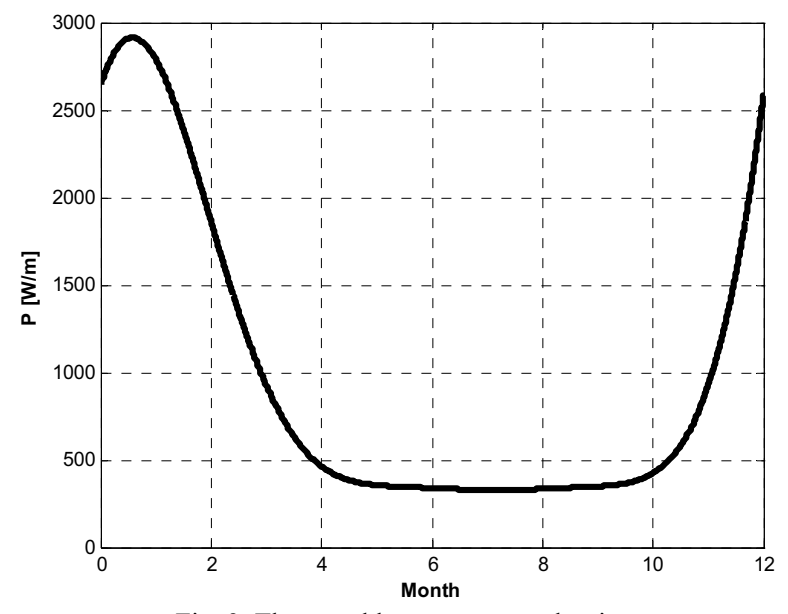

Fig. 3. The monthly mean power density

As it can be seen the wave energy density is the highest winter and autumn, fortunately coinciding with the greatest energy demands.

The mean value of the power density was found out to be about $1 \mathrm{~kW} / \mathrm{m}$. This low power density is compensated by relatively small wave power variability as compared with the seas with peak wave power densities.

Taking into account the various advantages of the electrical power generation from waves it can be stated out that also at this relatively small wave energy potential the exploitation of the wave energy could be of real interest.

\section{WAVE ENERGy CONVERTERs In THE Black SEA}

The potential wave power can be converted to electricity via mechanical means. Harnessing the energy provided by oceanic waves has been developed for over the past thirty years via numerous technologies.

Several power take off systems, called Marine Energy Converters (MECs), were already proposed [6]. The most complicated constructions are with direct mechanical linkage, with pneumatic (for example the Oscillating Water Column system [12]) or with hydraulic systems (as Pelamis [7]).

The direct drive power take off system, which is proposed also by our research team is very simple. It has the electrical generator and moving part of the power take off system joined together with no intermediate mechanical systems.

The simplest such system uses a floating buoy connected to linear generator and work upon the difference in height between wave top and wave bottom. These converters can be configured in many different ways in order to fit their performances to the requirements and to the given environmental conditions.

As it was stated out previously the buoy, floating on surface of the water, follows the motion of the wave [13]. It is connected to a linear generator fixed on a concrete 
foundation, which stands on the bottom of the sea (as shown in Fig. 4).

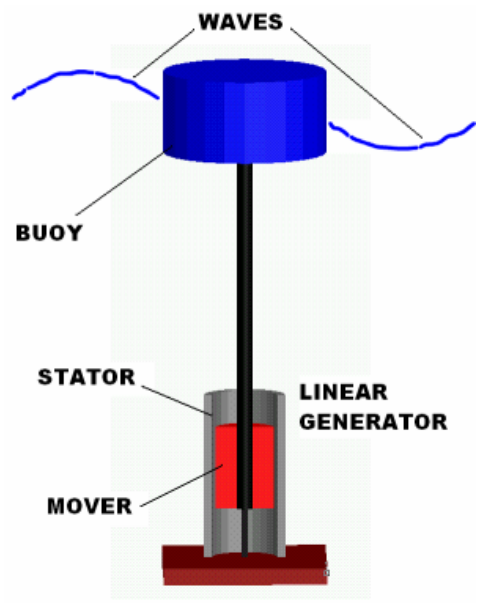

Fig. 4. The floating buoy system with the linear generator

The system is mechanically simple, with a few moving parts. By optimizing the shape and operation of the buoy up to $90 \%$ absorption efficiency can be achieved [14].

The variable wave heights highlight one of the difficulties with such wave energy converters, namely the requirement of adaptability to different sea states. A device which is optimized for a given amplitude and frequency must be capable of surviving also in much rougher conditions.

Between the generator and the gird ac/dc, respectively dc/ac converters must be coupled, as shown in Fig. 5. The electric power is proposed to be transported via a dc net to the land, where the connection to the grid will be done.

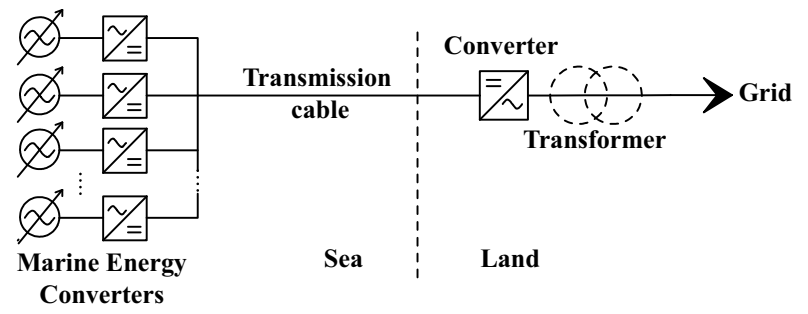

Fig. 5. The proposed the power system

The above presented electric system is only one of the numerous possible ones, and it was selected based on the specific circumstances regarding the placement of the wave power take off system near the Romanian shore of the Black Sea.

Several countries in the world have supported ocean energy development through R\&D programs and other support measures. The European Commission is playing an important role in coordinating the development of the technologies; hence also Romania should join the researches in this field. As in [15] is recommended, for Romania under the perspective of sustainable development better options than nuclear power are available for meeting the Romanian energy needs. These options are without the risk of disastrous accidents for the population, and do not generate long-term radioactive waste. The alternative energy options (among these also the wave energy) provide new opportunities for the Romanian population: decrease of energy expenditure, creation of new jobs and protection of the environment.

Romanian specialists have vast experience in offshore oil industry technology, which could be fructified in such national projects. It should be also mentioned, that several components of a $2 \mathrm{MW}$ Archimedes Wave Swing (AWS) system to be installed in Portugal were manufactured in Romania and were floated round to Portugal in 2002 [15].

Many of the known wave energy converter systems consist of large mechanical structures, often located near the sea surface. Studying the particularities of the Black Sea near the Romanian coast we concluded that it should be more efficient to install wave power plants consisting of large arrays of small wave energy converters (of about tens of $\mathrm{kW}$ ) having specifically designed linear generators driven by a point absorbing buoy [8].

\section{LINEAR GENERATORS FOR WAVE ENERGY CONVERTERS}

The crucial part of such marine renewable energy devices is the efficient conversion of kinetic energy into electrical energy.

Linear generators can extract power in the form of a reciprocating motion at low speed. Direct extraction of this low speed, high torque energy is possible, but the electrical output (voltage) will need some electronic processing of the waveform to enable grid connection.

Hence the optimal design of the linear generator used in such a system, the main topic of our research, is a very important issue in the development of the entire power plant.

In the literature mainly the following linear generators are proposed for wave energy converting power plants:

v.) Linear permanent magnet synchronous machines [16], both with surface and buried permanent magnets.

vi.) Vernier hybrid linear machines [17], [18].

vii.) Air cored permanent magnet tubular linear machines [6], [19].

The descriptions and the performances of the above mentioned machines had been studied from the point of view of their applicability in the power plants intended to be placed in the Black Sea.

The linear generators to be applied must have low power (of order of $\mathrm{kWs}$ ), they have to work at low speeds (up to $1 \mathrm{~m} / \mathrm{s}$ ) and to have short strokes (under $1 \mathrm{~m}$ ). Of course as they are placed under the water in hard to mount and to access places they have to be maintenance free and to have great force density in order to have as low mass and volume as possible.

In this paper an air core and an iron cored variant of the tubular permanent magnet linear generators will be proposed and compared by means of numeric field computations. 
The structures of the two tubular permanent magnet linear generators in study are given in Fig. 6.

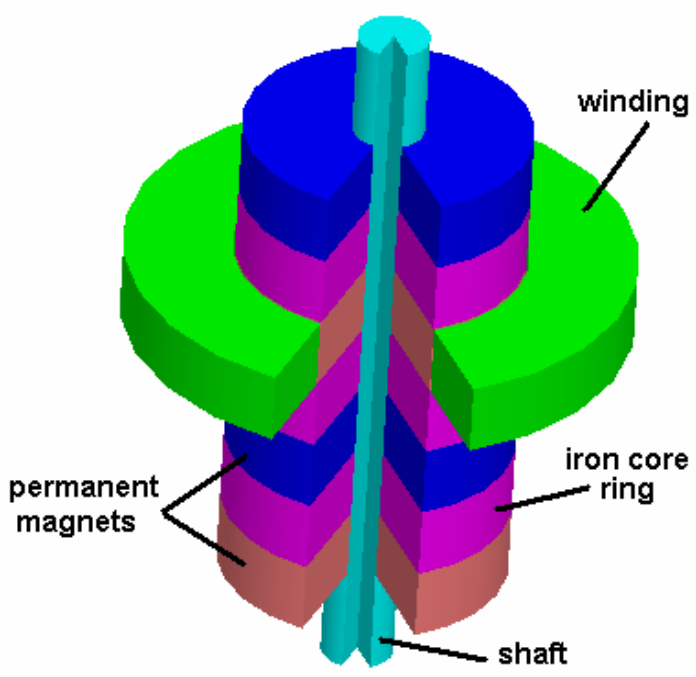

a) the air-cored structure

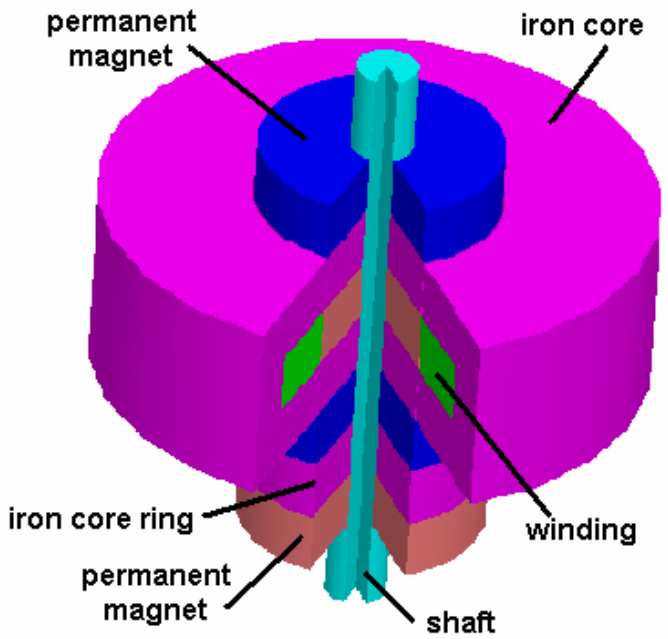

b) the iron-cored structure

Fig. 6. The structures of the two tubular permanent magnet linear generators taken into study

The mover of the two linear generators in study is identical. It consists of iron core rings fixed on a shaft alternated with permanent magnet rings magnetized in radial direction. The neighbored permanent magnets have different sense of magnetization; hence strong magnetic flux is generated outside the moving armature.

In the outer part of the linear generator the winding is placed. By moving the armature with the permanent magnets inside the winding a varying magnetic flux will pass through it, generating emf, which can be collected on the terminals of the winding. In the case of the iron cored structure the winding is closed in an iron core structure having U-shaped cross-section, Fig. 6b, for better concentrating the magnetic fluxes generated by the permanent magnets.

The main characteristics of the two linear generators in study were obtained via precise numeric field computations. For this purpose the JMAG finite elements method based software package was used [20].
In order to reduce at this stage of the researches the time of the simulations in both cases the 2D axial symmetric transient analyses of the two linear generators was performed.

The mesh generated automatically by the program over the two machine structures are given in Fig. 7.

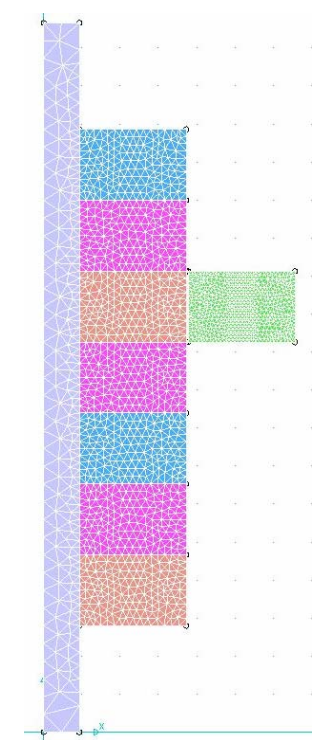

a) the air-cored generator

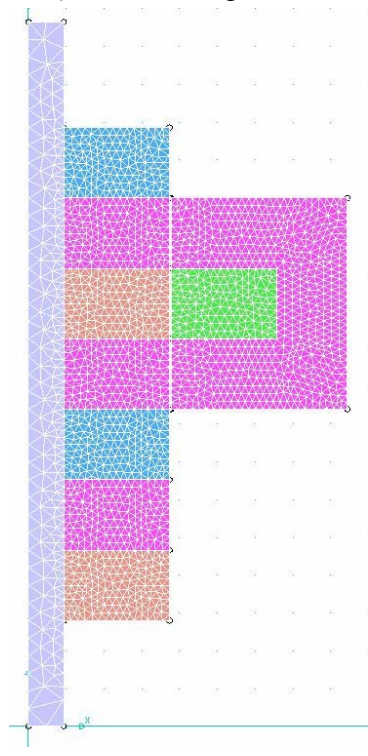

b) the iron-cored generator

Fig. 7. The meshes generated by JMAG program

Next the main results obtained via the field computations will be given. At first in Fig. 8 the obtained field lines are shown. Only those inside the machine are given.

As a transient analysis was performed the field lines were obtained in numerous positions of the mover. Here only the field lines in two distinctive positions of the mover will be given: when the air cored linear generator has its poles aligned, respectively perfectly un-aligned with the iron core rings of the mover. In order to be able to compare the obtained results for the air-cored generator the field lines will be given for the same positions. 


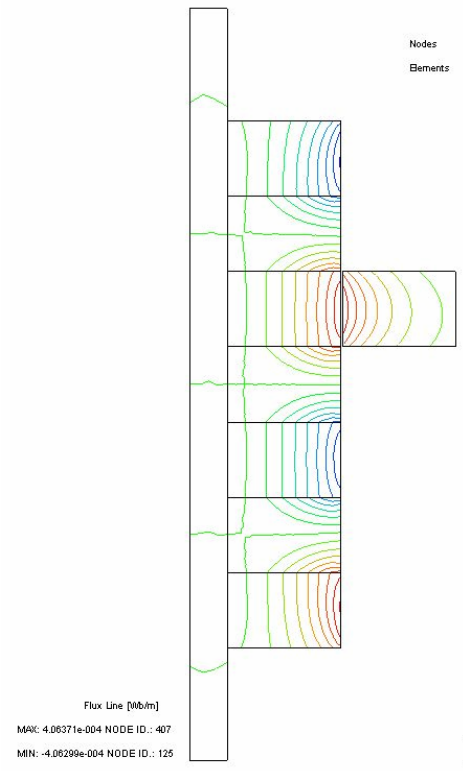

aligned

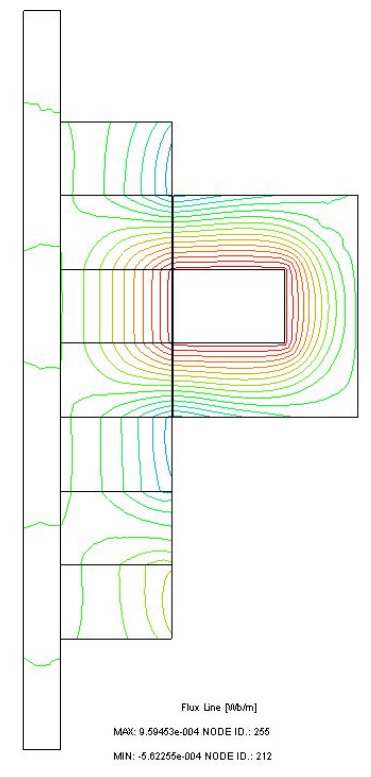

aligned

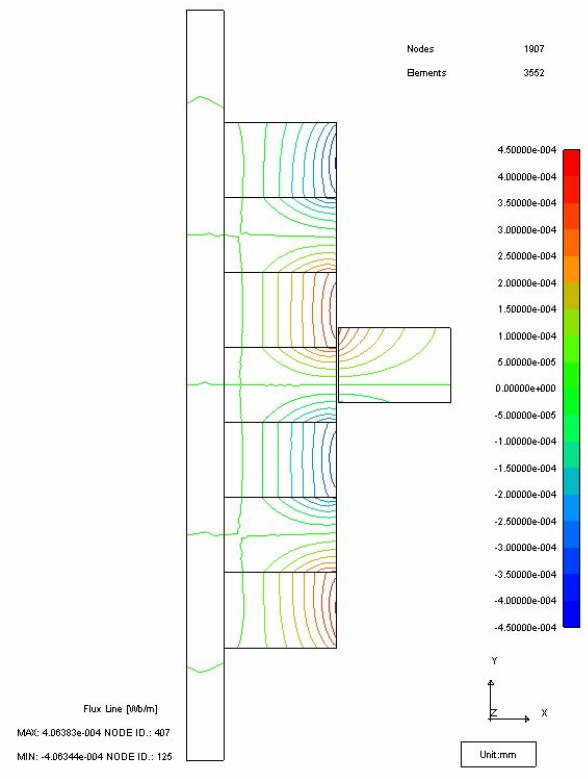

unaligned

a) the air-cored linear generator

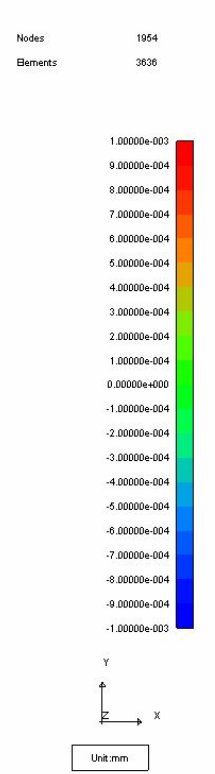

b) the iron-cored linear generator

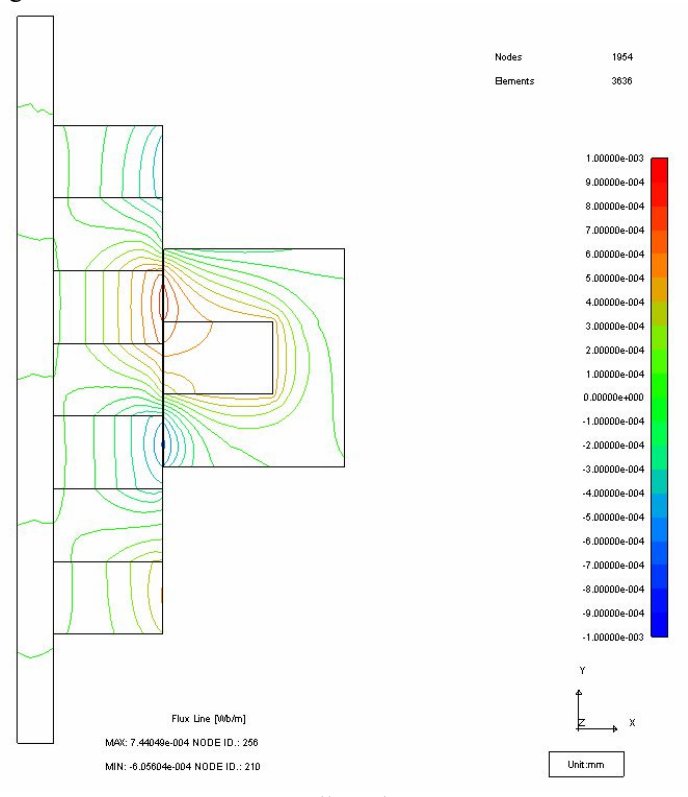

unaligned

Fig. 8. The field lines obtained via field computations

It can be easy seen that the change of the magnetic flux inside the iron core housing the coil during the $1 \mathrm{~m} / \mathrm{s}$ constant speed movement of the armature is much greater than in the case of the air-cored linear generator. Therefore also the generated voltage it is expected to be greater.

Next the induced voltages in the coils of the two linear generators taken into study are given in Fig. 9. It should be mentioned that in order to be able to compare the machines identical coils were used in both linear generator variants.

As it can be seen in Fig. 9 the voltage generated in the iron-cored permanent magnet tubular linear generator is much greater than in the case of the air-cored variant in study.

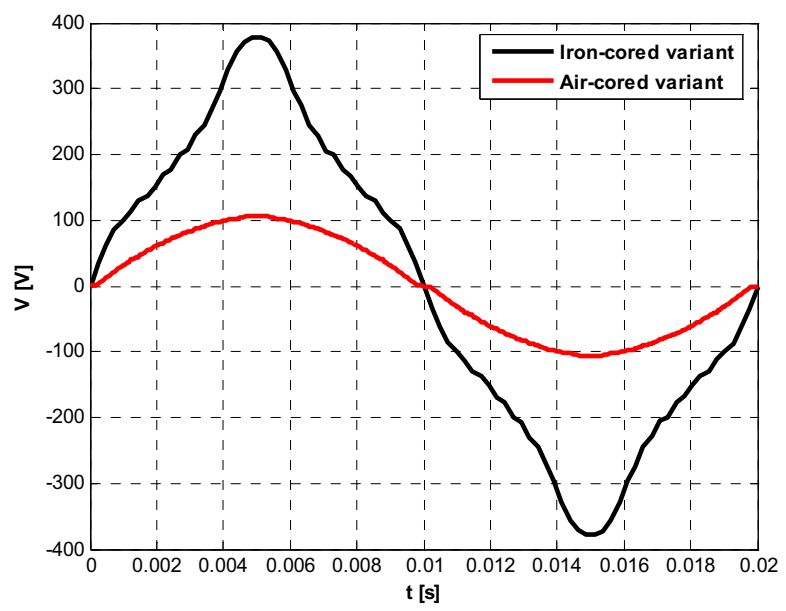

Fig. 9. The induced voltages in the windings 
The peak value of the induced voltage in the iron-cored variant is near 3.6 times greater than in the other case. The ratio of the RMS values is also great:

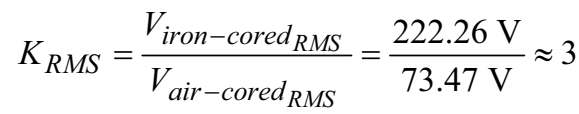

But also an other difference of the two generated voltages can be seen in the same figure: as far as the voltage in the case of the air-cored linear generator variant has a near sinusoidal shape, in the other case the voltage has serious harmonic content due to the non-linear magnetic property of the iron core surrounding the winding of the generator. This disadvantage in this certain application it is not very significant, because the windings are not connected directly to the grid. The power electronic devices connected between the generator and the grid can correct the harmonic content of the induced voltage in order not to introduce perturbations in the network.

\section{CONCLUSIONS}

All the obtained results emphasize the correct concept of the proposed linear generators and the advantages of using iron-cored linear generator constructions for such applications.

By minor changing in the design both the frequency and the amplitude of generated voltages can be changed in a manner as to fit also the requirements of the power electronic devices connected together.

In the future the analysis has to be extended also for sinusoidal variation of the speed, in order to simulate the real movement of the buoy displaced by the ocean waves. Also the control and the power system of the proposed marine power converter have to be designed.

\section{ACKNOWLEDGEMENT}

The work was possible due to the support given by the Romanian National Council of Scientific Research in Higher Education under grant A1305/2006 entitled "Linear Generators for Power Plants Using Renewable Wave Energy". The authors should like to sincerely thank this way for the financial support.

We also should like to thank to POWERSYS (France) for offering us a full-working trial of the JMAG electromagnetic field analysis software.

\section{REFERENCES}

[1] Schock, R.N., "Energy Technologies for the 21st CenturyThe Roles of Renewable Energy," Proceedings of the World Federation of Scientists International Seminars on Planetary Emergencies, Erice (Italy), 2005, URL: http://www.osti.gov/bridge/servlets/purl/875935-UcGgAW /875935.pdf.

[2] "Global wind energy markets continue to boom - 2006 another record year," Press release of Global Wind Energy Council (GWEC), Bruxelles (Belgium), 02.02.2007. URL: http://www.gwec.net/uploads/media/07-02_PR Global Statistics 2006.pdf.
[3] Callaghan, J., "Future Marine Energy Results of the Marine Energy Challenge: Cost competitiveness and growth of wave and tidal stream energy," Research Report, Carbon Trust, London (UK), 2006. URL: http://oreg.ca/docs/Carbon\%2Trust\%20Report/Future MarineEnergy.pdf.

[4] Thorpe, T.W., "An Overview of Wave Energy Technologies" Report AEAT-3615, Office of Science and Technology, AEA Technology, 1999.

[5] Previsic, M., Bedard, R., and Hagerman, G., "Offshore Wave Energy Conversion Devices," Electric Power Research Institute (EPRI) Report no. WP-004-US, Palo Alto (USA), 2004.

[6] Baker, N.J., "Linear Generators for Direct Drive Marine Renewable Energy Converters," Ph.D. thesis, School of Engineering, University of Durham (UK), 2003.

[7] ***, "2004 Survey of Energy," World Energy Council, London (UK), 2004.

[8] Bernhoff, H., Sjöstedt, E., and Leijon, M., " Wave energy resources in sheltered sea areas: A case study of the Baltic Sea," Proceedings of the $5^{\text {th }}$ European Wave Energy Conference, Cork (Ireland), 2003.

[9] Soomere, T., "Wind wave statistics in Tallinn Bay," Boreal Environment Research, vol. 10 (2005), Helsinki (Finland), pp. 103-118.

[10] Barstow, S.F., et al., "WORLDWAVES: High Quality Coastal and Offshore Wave Data Within Minutes for any Global Site," Proceedings of $22^{\text {nd }}$ International Conference on Offshore Mechanics and Arctic Engineering OMAE '03," Cancun (Mexico), pp. 23-32, 2003.

[11] Lopatoukhin, L.J. et al., "Estimation of Extreme Wind Wave Heights," Joint Technical Commission for Oceanography and Marine Meteorology (JCOMM) Technical Report No. 9 (WMO/TD-No. 1041), 2000.

[12] Leijon, M, "Multi-Physics Simulation of Wave Energy to Electric Energy Conversion by Permanent Magnet Linear Generator," IEEE Transactions on Energy Conversion, vol. 20 (March 2005), no. 1, pp. 219-224.

[13] Mueller, MA, et al., "Low Speed Linear Electrical Generators for Renewable Energy Applications," Proceedings of the Conference on Linear Drives in Industrial Applications (LDIA '2003), Birmingham (UK), pp. 121-124.

[14] Thorburn, Karin, Bernho, H., Leijon, M., "Wave energy transmission system concepts for linear generator arrays," Ocean Engineering, vol. 31 (2004), pp. 1339 -1349.

[15] Wenisch, A., Pladerer, C., "Energy Situation and Alternatives in Romania," Austrian Institute for Applied Ecology, Wien (Austria), 2003. URL:http://www.protectiamediului.ro/en/ nuclear/cernavoda2npp/energy.html.

[16] Yokobori, K., "Survey of Energy Resources," $19^{\text {th }}$ edition, World Energy Council, Tokyo (Japan), 2002.

[17] Danielsson, O., Thorburn, K., Eriksson, M., Leijon, M., "Permanent magnet fixation concepts for linear generator," Proceedings of the $5^{\text {th }}$ European Wave Energy Conference, Cork (Ireland), pp.117-124, 2003.

[18] Mueller, M.A. et al., "Dynamic Modelling of a Linear Vernier Hybrid Permanent Magnet Machine Coupled to a Wave Energy Emulator Test Rig," Conference Record of the International Conference on Electrical Machines ICEM '2004, Cracow (Poland), on CD: 495.pdf, 2004.

[19] Brooking, P.R.M., "Power conversion in a low speed reciprocating electrical generator," Conference Record of the International Conference on Electrical Machines ICEM '2002, Brugge (Belgium), on CD: 452.pdf.

[20] "JMAG-Studio 8.4 Tutorial," JRI Solutions, Ltd., Engineering Technology Division, Tokyo (Japan), 2006. 